\title{
Renewables vs. Energy Efficiency: the Cost of Carbon Emissions Reduction in Spain
}

\author{
Álvaro López-Peña', Ignacio Pérez-Arriaga, Pedro Linares \\ Instituto de Investigación Tecnológica \& Cátedra BP de Energía y \\ Sostenibilidad, Universidad Pontificia Comillas, Madrid, Spain \\ Registered Working Paper IIT-11-199A, version 1.0 \\ Paper submitted for publication to Energy Policy on December 5th, 2011
}

\begin{abstract}
:
While renewable support instruments have succeeded to deploy a large volume of installed capacity in Spain during the 1996-2008 period, little attention has been paid to energy efficiency measures, resulting in a high energy intensity and large growth of energy demand. As a consequence energy-related $\mathrm{CO}_{2}$ emissions have increased significantly, despite the also important investments in combined cycle gas turbines. In this paper we analyze whether, from a cost minimization viewpoint, renewable support has been the best policy for reducing emissions, when compared to the promotion of energy efficiency in sectors such as transportation or buildings. We use a model of the Spanish energy sector to examine its evolution in the time period considered under different policies. We conclude that demand side management clearly dominates renewable support instruments if reduction of emissions at minimum cost is the only concern, and we also quantify the savings that could have been achieved.
\end{abstract}

Keywords: $\mathrm{CO}_{2}$ emissions; renewable energy support; energy conservation.

\footnotetext{
'Corresponding author:

E-mail: Alvaro.LopezPena@iit.upcomillas.es

Address: Instituto Investigación Tecnológica. Santa Cruz de Marcenado 26, 28015 Madrid, Spain.

Phone: +34 915422800 Ext. 2775; Fax: +34 915423176
}

Page 1 of 33 


\section{Introduction}

Within the European Union (EU), and in spite of some recent improvements, Spain is among the worst placed countries to comply with their carbon reduction commitments for 2012. Although the EU burden sharing agreement allowed for an increase of 15\% compared to 1990 levels, Spanish emissions prior to the present crisis had grown by $50 \%$, and in 2009 were $27 \%$ above 1990 (Ministerio de Medio Ambiente y Medio Rural y Marino, 2011).

However, not all sectors have contributed equally to this negative evolution. The electricity sector, by massively introducing gas-based power plants and renewables, has been able to contain its emissions despite a large increase in demand: between 1996 and 2008, electricity demand grew by 72\% and $\mathrm{CO}_{2}$ emissions from power generation by 55\%. More than $21 \mathrm{GW}$ of combined cycle gas turbines (CCGTs) were installed between 2002 and 2008, making CCGTs share in total installed capacity increase from $0 \%$ to $24 \%$. The contribution of renewable capacity (excluding large hydro) grew from $11 \%$ to $25 \%$ in the same years, mainly due to the installation of $15 \mathrm{GW}$ of onshore wind power, what has made Spain become a leader in wind power. The support given to renewable electricity has also positioned Spain favourably towards meeting the European 2020 target for renewables, in spite of the large neglect of nonelectric renewables (Labriet et al., 2010).

This support for renewable sources of electricity production has been arguably the most effective public policy for the mitigation of carbon emissions in Spain, although it originally started with other motivations: reducing energy 
imports, curbing the emissions of other pollutants, job creation and technological development.

However, these advantages of renewable energies should not hide the fact that, at least in regard to carbon emissions reduction, other alternatives might have been more cost-efficient. In particular, Spain has a large potential for energy efficiency because of its high energy intensity (Mendiluce et al., 2010), particularly in the transport sector (Mendiluce \& Schipper, 2011) and also in the residential sector. From the standpoint of pure cost minimization, and ignoring the renewable targets derived from European policy, one has to question if it would have been preferable to prioritize public support for energy efficiency as a better means for $\mathrm{CO}_{2}$ emissions reduction in Spain.

The aim of this paper is to partially answer this question by comparing the cost of achieving the current emissions level through renewable electricity support or through energy conservation. We perform the comparison with an energy policy evaluation model applied to the 1996 - 2008 period in Spain. The results will allow us to confirm what appears to be a general consensus in the literature: that the most cost-efficient means of reducing carbon emissions (leaving aside important considerations such as industrial policy, security of supply, and other long-term issues) is to enhance energy efficiency (Enkvist et al., 2007). In particular, our study will allow us to quantify the actual magnitude of this increased cost efficiency, for a real country with a large penetration of renewable energy sources. 
The structure of the article is as follows. In section 0 we describe the main features of the model. Then we describe the considered scenarios for the analysis in section 3 and the results in section 4 . Finally, we draw the conclusions in section 5 .

\section{The methodology, the model and its main parameters}

In this section we present first an overview of the model used and the rationale behind our methodology. Then we provide further details on the data used, the characterization of demand and demand side management (DSM) measures, the representation of energy conversion technologies, the modelling of primary energy production and energy trade, and the characterization of energy networks. Finally, the computer implementation of the model, done in GAMS, is briefly introduced. For more detail on the numerical data refer to (López-Peña et al., 2011a).

\section{a. Overview}

To carry out the study, we have used POEMS, a policy-oriented model of the entire Spanish energy system (López-Peña et al., 2011b). It allows us to analyze the energy sector's evolution under different policy scenarios, specifically selected to answer our research question. POEMS is a bottom-up, static, partial equilibrium, linear programming model of the energy sector. For each scenario, we calculate the least-cost energy supply for the country, given exogenous demands for each type of final energy in each subsector, and without exceeding a specified level of emissions. The cost to be minimized includes the main private costs (no externalities) involved in the energy sector: domestic 
primary energy purchases, energy imports and exports, investments in energy assets or their fixed and variable costs, among others. The main outputs of the model include the energy flows through the entire energy system, its emissions, the required investments, and all the associated costs.

The study covers the $1996-2008$ period, which has been chosen so that the renewable electricity $(\mathrm{RE})$ development is included from its beginning, while the main effects of the economic crisis on energy demand, which may significantly affect the results, are left out (the main decrease in demand started in 2009). The installed capacity of all power generation technologies (and other energy conversion technologies) in 1996 is an input to the model, while the final energy demands that must be supplied are those of 2008. The model then searches for the minimum-cost supply of the 2008 demand, with the 1996 capacities as input, for which it must determine the investments that are required to satisfy the increase of demand in the period. The solution of the model is constrained so that the computed $2008 \mathrm{CO}_{2}$ emissions cannot be higher than the actual ones. This prevents the model from investing in carbon-intensive technologies, even if they were the best choice to meet the increment of demand at a minimum cost. In other words, the model calculates the investments that, under the assumptions of perfect energy markets and rational policymaking (implicit in the optimization), should have occurred in Spain between 1996 and 2008 to minimize the cost of supplying the 2008 energy demand without exceeding that year's historical emission level. The perfect energy markets hypothesis is a reasonable one in the long term, and it is 
therefore widely used in energy systems analysis models, such as the MARKAL/TIMES family (Fishbone \& Abilock, 1981; Loulou et al., 2005). The second assumption, rational policymaking, is indeed what allows us to perform this analysis, since the aim is to identify the policies that should have been implemented from such a perspective.

\section{b. Data used}

Given that a period of twelve years is represented through a static model, certain precautions must be taken with the data used. The technologies' costs and the prices of primary and final energy in international markets are the average 1996 to 2008 values, measured in constant 2008 Euros. The capacities of gas and electricity interconnections are the average values observed in the period and the model cannot invest in increasing them; in this way the model tries to capture the administrative difficulties that this kind of projects have encountered in the past years in Spain.

\section{c. Demand and DSM characterization}

We must characterize demand side management (DSM) policies within the model in order to compare them with RE support policies and therefore be able to answer this paper's research question. In order to do this, we have created a database of DSM policies, and their potential effects and associated costs are included in Table 1. The database only includes those measures that would have been technologically feasible at reasonable costs during the studied period. This implies that some of the measures that are envisaged for the future, such as the support for massive penetration of electric vehicles, are left out. These DSM 
measures have been characterized using the results from several studies that analyze the potential of energy efficiency measures in Spain: (de la Villa, 2010), (Fraunhofer ISI et al., 2009), (Lorenzo, 2010), (Ministerio de Fomento, 2011), (Ministerio de Industria, Turismo y Comercio, 2011), (WWF Spain, 2010). We have calculated the cost of implementing them as the additional cost that the country would have to pay to implement the measure (i.e. the marginal social cost), other things being equal. Fiscal measures are considered to have zero cost, assuming that they do not involve significant distortions in the economy. The effects of measures that act over several years have been standardized for one year, and their associated costs too, by calculating the annuity of the investment from the perspective of the government, i.e. low interest rate $(5 \%)$ and low payback period (10 years). We have assumed the rebound effect of final energy efficiency gains, if any, to be small or already incorporated in the estimated reduction of demand, as it was the case in (Linares et al., 2008) for the Spanish electricity sector. For electricity, and other final energy sources too, this assumption can be supported by the low estimates of this effect that are observed in OECD households' demand for personal transport, heating or cooling (Sorrell et al., 2009); or in households and firms in the US (Greening et al., 2000). Moreover, if we assume that DSM measures are promoted through price signals, then the rebound effect will be minimized. 
IIT Working Paper IIT-11-199A

Renewables vs. Energy Efficiency: the Cost of Carbon Emissions Reduction in Spain Paper submitted to Energy Policy on December $5^{\text {th }}, 2011$

\begin{tabular}{|c|c|c|}
\hline Description & Cost (M€) & Effects \\
\hline "Eco Driving principles for car drivers" & 2.0 & $-1 \%$ gasoline and diesel demand in road transportation \\
\hline "Teleconference incentives for businesses" & 1.3 & $\begin{array}{l}-2.5 \% \text { kerosene demand in air transportation, }-1 \% \text { diesel and } \\
\text { gasoline demand by cars, }-0.01 \% \text { electricity demand by trains }\end{array}$ \\
\hline "Promote correct tyre inflation in cars" & 2.0 & $-1 \%$ gasoline and diesel demand in road transportation \\
\hline "7\% share of biofuels in $2008 "$ & 0.0 & $-5 \%$ gasoline and diesel demand in road transportation in 2008 \\
\hline "Promote fuel saving devices in cars" & 68.0 & $-2 \%$ gasoline and diesel demand in road transportation \\
\hline "Promote urban biking in cities bigger than 200k" & 33.4 & $-0.13 \%$ gasoline and $-0.03 \%$ diesel demand in road transp. \\
\hline "Promote car scrapping" & 13.0 & $-2.2 \%$ gasoline and $+0.4 \%$ diesel demand in road transportation \\
\hline "Install regenerative brakes in subway" & 3.4 & $-3 \%$ electricity in train transportation \\
\hline "Rise fuel taxes for particular cars" & 0.0 & $-4 \%$ diesel, $-4 \%$ gasoline, $+0.0001 \%$ train electricity \\
\hline "Install access tolls in cities bigger than 200k" & 7435.0 & $-0.84 \%$ gasoline, $-0.29 \%$ diesel in road transportation \\
\hline "Improved air traffic operations" & 0.4 & $-1.82 \%$ kerosene, air transportation \\
\hline "Increase freight by railway, decreasing truck" & 971.0 & $-0.4 \%$ diesel in road transportation, $+20 \%$ electricity in train \\
\hline "Promote freight in ship in Athlantic coast" & 3.9 & $-0.24 \%$ diesel in road transportation \\
\hline "Rational lighting systems residential sector" & 422.0 & $-29 \%$ electricity, residential sector \\
\hline "Rational cooling systems residential sector" & 7498.0 & $-24 \%$ electricity, residential sector \\
\hline "Rational heating systems residential sector" & 227.0 & $-15 \%$ electricity, residential sector \\
\hline "Efficient appliances residential sector" & 1191.0 & $-2 \%$ electricity, residential sector \\
\hline "Efficient electronics residential sector" & 97.0 & $-3 \%$ electricity, residential sector \\
\hline "Efficient tyres for cars" & 360.0 & $-1.5 \%$ gasoline and diesel demand in road transportation \\
\hline "Efficient boilers for residential sector" & 932.4 & $\begin{array}{l}\text {-10\% in liquefied petroleum gases (LPGs), natural gas, diesel and } \\
\text { biomass demand, redidential sector }\end{array}$ \\
\hline "Improved thermal insulation for residential sector" & 6475.0 & $\begin{array}{l}-9.4 \% \text { in LPGs, natural gas, diesel and biomass demand, resid. } \\
\text { sector }\end{array}$ \\
\hline "Double windows in residential sector" & 5180.0 & -14\% in LPGs, natural gas, diesel and biomass demand, resid. \\
\hline "In-floor radiating heating devices in resid. sector" & 6734.0 & $-2.4 \%$ in LPGs, natural gas, diesel and biomass demand, resid. \\
\hline "Solar thermal water heating in residential sector" & 3108.0 & -19\% in LPGs, natural gas, diesel and biomass demand, resid. \\
\hline
\end{tabular}

Table 1. Demand side management policies database.

As said above, the model's main aim is to supply 2008 historical final

energy demands (inputs to the model) while not exceeding actual carbon

emissions in that year and minimizing supply costs. The final energy demands in

2008 have been obtained from (Instituto para la Diversificación y Ahorro de la

Energía, 2009). Demand is considered inelastic, except for the possible

reductions arising from the application of DSM policies, which the model may

decide to apply if they happen to be of interest from the cost-minimization

perspective, i.e. if the associated benefits are greater that the implementation

costs, what happens often as shown in (Gillingham et al., 2006). The adopted

demand values are shown in Table 2. 


\begin{tabular}{|c|c|c|c|c|c|c|c|c|c|c|c|c|c|}
\hline PetaJoules (PJ) & Electricity & Coal & Nat. Gas & Gasoline & Diesel & Fuel Oil & LPGs & Kerosene & Other Oil Prods. & Biofuels & Biomass & TOTAL & $\%$ \\
\hline Industry: MCM* & 203 & 74 & 218 & 0 & 14 & 14 & 4 & 0 & 85 & 0 & 6 & 618 & $15 \%$ \\
\hline Industry: Chemistry & 49 & 9 & 138 & 0 & 4 & 7 & 7 & 0 & 3 & 0 & 1 & 218 & $5 \%$ \\
\hline Industry: Other & 142 & 3 & 169 & 0 & 21 & 22 & 3 & 0 & 0 & 0 & 55 & 415 & $10 \%$ \\
\hline Primary Sector & 20 & 0 & 11 & 0 & 104 & 2 & 3 & 0 & 0 & 0 & 1 & 141 & $3 \%$ \\
\hline Residential Sector & 232 & 1 & 151 & 0 & 118 & 9 & 89 & 0 & 0 & 0 & 86 & 686 & $17 \%$ \\
\hline Tertiary Sector & 261 & 0 & 30 & 0 & 71 & 5 & 13 & 0 & 0 & 0 & 3 & 384 & $9 \%$ \\
\hline Road Transportation & 0 & 0 & 0 & 268 & 1015 & 0 & 1 & 0 & 0 & 27 & 0 & 1310 & $32 \%$ \\
\hline Railway Transp. & 20 & 0 & 0 & 0 & 29 & 0 & 0 & 0 & 0 & 0 & 0 & 49 & $1 \%$ \\
\hline Air Transp. & 0 & 0 & 0 & 0 & 0 & 0 & 0 & 242 & 0 & 0 & 0 & 242 & $6 \%$ \\
\hline Sea Transp. & 0 & 0 & 0 & 0 & 50 & 8 & 0 & 0 & 0 & 0 & 0 & 58 & $1 \%$ \\
\hline TOTAL & 926 & 87 & 717 & 268 & 1426 & 67 & 120 & 242 & 89 & 27 & 153 & 4123 & $100 \%$ \\
\hline$\%$ & $22 \%$ & $2 \%$ & $17 \%$ & $7 \%$ & $35 \%$ & $2 \%$ & $3 \%$ & $6 \%$ & $2 \%$ & $1 \%$ & $4 \%$ & $100 \%$ & \\
\hline
\end{tabular}

Table 2. 2008 final energy demands per type and demanding sector, in PetaJoules.

\section{d. Representation of energy conversion technologies}

We now describe energy conversion technologies (power generation, oil refining and LNG gasification). The electricity subsector must be represented in great technological detail, in order to capture the performance of the RE technologies whose support is being assessed in this paper. Power generation is represented by the twenty-two technologies that are relevant to the Spanish case: nuclear, two coal types (domestic and imported), three types of hydro, hydro pumping stations, combined cycle and open cycle natural gas turbines, fuel-gas generators, three types of onshore wind with different quality resource and different maximum potential, one type of offshore wind, three types of biomass, solid waste, solar photovoltaics and concentrated solar power.

Increasingly related to the power sector by the large amount of gas-based generation, LNG regasification must be modelled too. For that, a single reference regasification terminal is used. Its investment and operating costs, efficiencies and emissions are the average values of Spanish terminals. The model is 
provided, as input, with the 1996 regasification capacity, and can invest in new capacity.

Oil refining is less critical for this study, but as the model covers the entire energy sector, it is modelled too. Three benchmark refineries are used according to their complexity: medium, high and very high. The greater the complexity, the greater the flexibility in obtaining different oil products and the larger the achievable proportion of high value added products (such as gasoline and kerosene). However, greater complexity means larger investment and operating costs, higher losses and higher emissions. For the sake of simplicity and seeking to focus on the specific objectives of the study, we have used the 2008 Spanish refining capacity, considering it as fixed, and a single crude oil quality is represented.

Given that this model is a bottom-up one, the modelled energy conversion technologies must be characterized in economic and technological terms. Each of them has associated parameters in order to represent their investment costs, payback period and required rate of return ( $9 \%$ for all technologies, except $15 \%$ for nuclear to account for its higher risk premium); variable and fixed operation and maintenance costs; previously installed capacity and new capacity limitations (if any); and losses and emissions factors. The fuel costs are accounted for, from a national perspective, in the costs of energy imports. We have modelled the RE technologies by using load factors and capacity limitations, which depend on the quality of the primary energy resource. Wind power is, for instance, modelled with three load factors of decreasing value, each of them 
having a capacity limitation, which represents the resource potential at each resource level. Hydro power generation capacity has been frozen at its 1996 value, when it had almost reached its full physical potential.

\section{e. Primary energy production and trade modelling}

Limitations on the annual availability of domestic primary energy have been introduced for domestic coal, biomass and hydropower. We have obtained their values through the extrapolation of average historical values. The costs associated with domestic primary energy production (coal mining and biomass processing) and coal mining emissions are considered too.

Unlimited import and export capacity is assumed for all primary and final energies traded in Spain, except for gas pipelines and electricity interconnections with North Africa and Europe, where the average 1996-2008 capacity is used, as stated above. We have assumed biofuels to be entirely imported, and biomass for heat and electricity to be entirely domestic.

\section{f. Energy networks}

For the electricity, natural gas and oil products transport networks, we have used a single-node representation, and for all of them unlimited energy transportation capacity has been assumed. However, the model considers for each network an average losses factor and a cost per transported energy unit.

When modelling large electricity systems, special attention must be paid to the precision in the representation of temporal variations in their operation, and to the requisites for technical reliability of the system. Concerning temporal 
variations, 96 load levels have been used to represent electricity demand throughout the year with enough precision: 12 months, two day types within each month (week day/weekend), and four load levels per day (including a super-peak one representing the $1 \%$ hours with the highest demand values in each day type). This time representation has been also useful to model seasonal variations in the demand of other final energy types such as oil products or natural gas.

In order to collect the three technical dimensions intervening in the reliability of power systems (as described in Batlle et al., 2007), the power generation technologies in our model are affected by two additional constraints: adequacy and reserves. Our adequacy constraint includes what these authors consider adequacy and firmness, while our reserves constraint refers to what they call security. Our adequacy constraint forces the model to invest enough in order to maintain a reserve margin of $20 \%$ of firm capacity over the year's peak demand. This value is similar to the one actually present in the Spanish system in 2008, according to (Red Eléctrica de España, 2009). This firm capacity is computed by multiplying each technology's installed capacity by a statistical firm capacity factor (external parameter), which represents the amount of firm capacity that each installed gigawatt provides to the system (e.g. wind power has a $7.5 \%$ value whereas coal generation has a 95\%). Our reserves constraint requires active generators with operational flexibility to provide sufficient operating reserves to the system. These reserves must be enough to cover the average load uncertainty in the system. This value is composed by the mean 
demand-forecasting error (assumed to be $4 \%$ of demand in each load level), the capacity of the largest power plant that could fail (1000 MW), and the prediction error in the production of intermittent technologies (assumed to be $20 \%$ of the average annual production). These two constraints aim, also, at representing the technical challenges of operating large power systems with high penetration of intermittent generation. As this model represents the entire energy sector in the long run, the technical detail of the operation of these systems is not represented in more detail. However, we believe that these two constraints give enough realism to the model.

In our model, we have considered also the technical constraints of the gas network. Assuming constant pressure and ignoring storage capacity of the gas pipelines, a simple energy balance in the network is deemed enough.

\section{g. GAMS implementation}

To avoid infeasibilities in the model, we have introduced the possibility of having unserved demand. This does not try to model the lost utility for society; it is instead only a slack variable for modelling purposes, which is highly penalized in the objective function. Trying to model the utility of energy demand would have the advantage of leaving the model the possibility of not supplying all demand if the system becomes tight and therefore the cost of supplying it is bigger than the utility given to it by society. However, estimates of energy use utility in literature are quite varied, and in this model values for all types of final energy would be needed (not only for electricity), so we have decided to not include this possibility. 
As already mentioned, this model is programmed in GAMS, and it is solved with CPLEX. For the data used in this study, it is a linear programming model with about 140,000 single equations and 140,000 variables. In a computer with an Intel Core2 Quad processing unit (four processors at $3 \mathrm{GHz}$ each) and $3.2 \mathrm{~GB}$ of RAM memory, data reading from Excel and model generation takes around 4 seconds, and then it is solved by CPLEX in 0.2 seconds.

\section{Scenarios considered}

We will answer our research question by running the model for different scenarios. Three main scenarios are considered. The first one (labelled "Base" as seen in Table 3) reproduces the actual situation in the study horizon, where RE was supported and additional DSM measures were not used. With that purpose, we have used constraints in order to force the model to invest, in each renewable technology, its actual 2008 capacity. Four RE constraints are used, one per technology (wind, biomass, solid waste and solar photovoltaic), and each imposing the installed capacity to be equal to the actual 2008 one. In this first scenario, DSM is not allowed. The second scenario (called "No RE") aims at isolating the effects of RE promotion and DSM promotion: it does not force the model to invest in renewables, and it does not allow it to use DSM either. It represents the situation where renewables are not supported, hence they compete freely in the market, and DSM is not possible. The third scenario is labelled "Efficiency" because it does allow the use of DSM, and does not force $\mathrm{RE}$, so it gives the model full flexibility to decide the best strategy to follow. 
Moreover, considering that the strong investment in CCGTs over the period of the study (21GW) may have a major impact on the results of the model, it is of interest to understand what would had happened should this large deployment of CCGTs had not taken place. Hence, we study the above-mentioned three scenarios under two different circumstances (identified by dark and light grey in Table 3): the actual investment in CCGTs (21GW) and free investment in CCGTs ("low CC" cases). This is done by using, in the first case, a constraint that forces the model to invest in $21 \mathrm{GW}$ of CCGT plants; while in the second group the volume of investment in CCGT is not forced, it is freely decided by the model.

\begin{tabular}{|c|c|c|c|c|}
\hline Scenario & RE forced & DSM allowed & CCGTs forced & Emissions constraint \\
\hline Base & Yes & No & Yes & No, "Actual2008" value obtained \\
No RE & No & No & Yes & Actual2008 \\
Efficiency & No & Yes & Yes & Actual2008 \\
Base_low CC & Yes & No & No & Actual2008 \\
No RE_low CC & No & No & No & Actual2008 \\
Efficiency_low CC & No & Yes & No & Actual2008 \\
\hline
\end{tabular}

Table 3. Scenarios considered.

As said before, the model minimizes the total energy supply cost in 2008 but cannot exceed the historical 2008 emissions. Hence, an emissions limit must be introduced. For calibration purposes, this limit is obtained by executing the "Base" scenario with unbounded emissions. In this case, installed capacities are the actual ones (CCGTs and REs are forced into the model) and additional DSM measures are not allowed (as happened in reality). Hence this scenario should provide a similar emissions value to the historical one. This would also confirm that the perfect energy market hypothesis implicit in the optimization represents reality over the long term well enough. After this calibration phase, the obtained emissions value from this scenario (labelled "Actual2008") is set as a limit for the 
other five cases. Additionally, during the study horizon, a slight increase in nuclear installed capacity took place, due to technological upgrades of the existing plants (from 7.4GW to 7.72GW).

\section{Results}

In this section, the results of the model for the six scenarios will be reviewed under the perspective of our research question. First, the results on carbon emissions will be explained, in order to understand where emissions are being produced, how the limit on them is bounding the model's results and which scenarios represent the cheapest ways of achieving the required emissions level. Second, the investments decided by the model under each case will be discussed. The aim here is to understand the investments that should have taken place for achieving the desired emissions in the most cost-efficient ways under each scenario. The discussion on the shadow prices of the constraints defining the different scenarios will also provide insightful information on which technologies are being more useful to achieve the desired goal. Then, the electricity generation under each scenario will be described, helping to better understand the model's behaviour. Finally, the total energy supply cost and its components will be discussed, helping us to understand how different costs interact and why the cheapest ways of achieving the desired emissions levels are, indeed, the cheapest. The combination of all these discussions on the results will allow us to provide an answer to this study's research question, which is done in the conclusions section. 


\section{a. Carbon emissions}

The results on carbon emissions in each scenario are shown in Table 4.

\begin{tabular}{|r|c|c|c|c|c|c|}
\hline Emissions $\left(\mathbf{M t}_{\mathbf{C O}} \mathbf{~}\right)$ & Base & No RE & Efficiency & Base_low CC & No RE_low CC & Efficiency_low CC \\
\hline Emiss. in primary energy production & 3.2 & 2.2 & 3.2 & 1.6 & 1.4 & 1.6 \\
Emiss. in energy conversion & 103.4 & 104.4 & 104.8 & 105.0 & 105.2 & 113.6 \\
Emiss. in final energy consumption & 209.3 & 209.3 & 200.7 & 209.3 & 209.3 & 200.7 \\
Total emissions & $\mathbf{3 1 5 . 9}$ & $\mathbf{3 1 5 . 9}$ & $\mathbf{3 0 8 . 7}$ & $\mathbf{3 1 5 . 9}$ & $\mathbf{3 1 5 . 9}$ & $\mathbf{3 1 5 . 9}$ \\
\hline Emiss. constr. shadow price $\left(\boldsymbol{€} / \mathbf{t C O}_{2}\right)$ & No constraint & -3.78 & 0.00 & -17.78 & -20.06 & -16.52 \\
\hline
\end{tabular}

Table 4. Carbon emissions in the different scenarios.

The emissions in the "Base" case (calibration scenario) were $315.9 \mathrm{MtCO}_{2}$, whereas the actual Spanish $\mathrm{CO}_{2}$ emissions from the energy system in 2008 were 310.6 $\mathrm{MtCO}_{2}$ according to (Ministerio de Medio Ambiente y Medio Rural y Marino, 2011). This is a $1.7 \%$ deviation, which is considered valid for this calibration step. Those $315.9 \mathrm{MtCO}_{2}$ are then used as emissions limit in the other five scenarios. This limiting constraint is active in all scenarios except in the "Efficiency" one. In them, total emissions take that precise value $\left(315.9 \mathrm{MtCO}_{2}\right)$ and the shadow prices associated to the constraint are not zero ${ }^{1}$. These shadow prices show how total energy system costs would decrease (negative value) when the emissions limit is made marginally looser. Or, to put it differently, they show the marginal cost of abating carbon emissions (which would correspond to a carbon allowance price for a Spain-only market). Interestingly, the values obtained are in the same order of magnitude of current EU Emissions Trading Scheme prices.

When the system does not have the $21 \mathrm{GW}$ of CCGT power plants ("Iow $C C^{\prime \prime}$ cases), the marginal abatement costs are larger, what points to the fact that CCGTs do indeed help in reducing emissions, as could be expected from the low 
specific emissions of burning natural gas, the high efficiencies of CCGTs, and the fact that in these cases there is considerably more installed capacity in the system. This abatement cost is smaller when the model can use demand side management ("Efficiency" and "Efficiency_low CC" cases) than when it is required to install renewables ("Base" and "Base_low CC" cases), what would imply that demand reduction measures are a cheaper way of reducing emissions than renewables promotion, a preliminary answer to this paper's research question. This confirms what has been said in the literature (Ecofys et al., 2009), (Enkvist et al., 2007). However, more results will be analyzed in order to reach a more comprehensive conclusion. In Table 4 we also show that, roughly, two thirds of Spanish emissions are produced in final energy consumption, while the other third belongs to energy conversion processes (mainly electricity generation and oil refining). Emissions in primary energy production (coal mining) are insignificant in comparison. In the "Efficiency" and "Efficiency_low CC" cases, the model reduces final energy consumption (because the costs of implementing the DSM measures are offset by savings, mainly in energy imports, as will be seen later). Hence final energy use emissions fall (from 209.3 to $200.7 \mathrm{MtCO}_{2}$ ), what makes the emissions constraint looser and the carbon marginal abatement cost falls. In the case with forced CCGTs and DSM allowed ("Efficiency"), emissions fall to a value of $308.7 \mathrm{MtCO}_{2}$, below the emissions limit, hence the zero value of the carbon marginal abatement cost. 


\section{b. Investments}

According to the model, in each of the six scenarios, the optimal capacity additions from 1996 to 2008 would have been the ones shown in Figure 1.

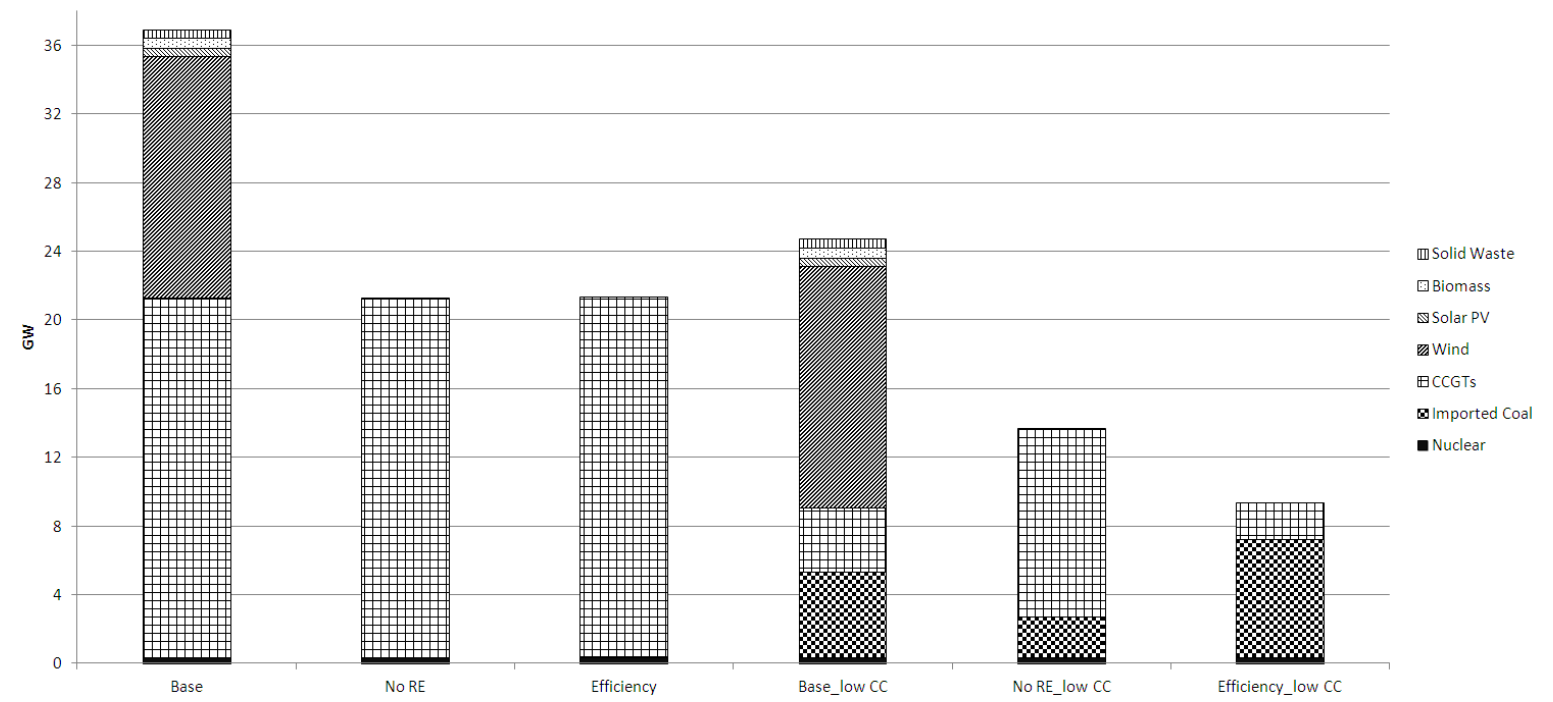

Figure 1. Capacity additions decided by the model for the studied period (1996-2008)

In the three cases where CCGTs are forced to the actual 21GW (scenarios not marked with the "low CC" label), the model does not add any additional capacity unless it is required to, what happens in the "Base" scenario (RE forced too). This fact points at the excess capacity that was indeed observed in the actual system, where CCGTs were functioning around 3000 equivalent hours per year.

In the other three scenarios (marked as "low $C^{\prime}$ "), the model prefers to invest in imported coal, until the emissions limit becomes tight, and then it invests in CCGTs. This is because of two reasons: (i) the lower prices of imported coal versus natural gas $\left(9.7 € / \mathrm{MWh}_{\text {ImportedCoal, }} 15 € / \mathrm{MWh}_{\text {NaturalGas, }} 18 € / \mathrm{MWh}_{\text {LNG }}\right)$; (ii) the long run effects (the ones affecting actual investment decisions) of 
European emissions trading, which reduce the competitiveness of coal versus gas, are not completely represented by our emissions limitation. Indeed, our cap on emissions is yielding carbon prices around $20 € / \mathrm{tCO}_{2}$ (the marginal carbon abatement costs seen above), which are lower than the ones presumably expected for the long run by agents operating under the actual European Trading Scheme (ETS). In addition, actual ETS prices are set at European level and only for carbon-intensive sectors, whereas in our model the emissions cap is applied at Spanish level and for the entire energy sector.

Continuing with the three "low CC" cases, the model can generate more electricity with coal in the case where DSM is allowed, because emissions from final energy use are lower, and therefore it invests more in coal in this case. The model does not invest in RE unless they are forced, and when that happens, it invests less in CCGTs (even in spite of the reserve requirements imposed to the model). An additional observation: the CCGT installed capacities in the three "low CC" cases are lower than the 21GW forced in the other three scenarios. This may imply that the large investment in CCGT capacity that took place (21GW) was suboptimal, as could have been guessed from the low functioning equivalent hours actually observed in the market and as already predicted in the literature (Linares et al., 2006).

\section{c. Shadow prices}

Useful information can be obtained from the shadow prices of the constraints $^{2}$ that impose the $21 \mathrm{GW}$ of installed CCGTs and the $2008 \mathrm{RE}$ capacities. By looking at each of the constraints' shadow prices (greater than and 
less than constraints), it is possible to identify which of the two take a positive value and hence if, from the optimization perspective, it would be better to decrease or to increase the required capacity. The results obtained for each constraint in the six scenarios are shown in Table 5.

\begin{tabular}{|l|c|c|c|c|c|c|}
\hline Shadow prices (€/kW) & Base & No RE & Efficiency & Base_low CC & No RE_low CC & Efficiency_low CC \\
\hline CCGT Capacity > & 91.09 & 78.37 & 87.29 & Not Applied & Not Applied & Not Applied \\
CCGT Capacity $<$ & 0 & 0 & 0 & Not Applied & Not Applied & Not Applied \\
Wind Capacity > & 113.19 & Not Applied & Not Applied & 82.26 & Not Applied & Not Applied \\
Wind Capacity< & 0 & Not Applied & Not Applied & 0 & Not Applied & Not Applied \\
Solar PV Capacity > & 469.40 & Not Applied & Not Applied & 436.90 & Not Applied & Not Applied \\
Solar PV Capacity $<$ & 0 & Not Applied & Not Applied & 0 & Not Applied & Not Applied \\
Biomass Capacity > & 188.33 & Not Applied & Not Applied & 45.36 & Not Applied & Not Applied \\
Biomass Capacity< & 0 & Not Applied & Not Applied & 0 & Not Applied & Not Applied \\
Solid Waste Capacity > & 391.05 & Not Applied & Not Applied & 372.88 & Not Applied & Not Applied \\
Solid Waste Capacity & 0 & Not Applied & Not Applied & 0 & Not Applied & Not Applied \\
\hline
\end{tabular}

Table 5. Shadow prices of the capacity constraints in $€ / \mathrm{kW}$, when applied.

The observation that can be made is that the less than constraints are never active, what implies that from the optimization perspective it would always be better to decrease capacity in CCGTs and RE. Given that the shadow prices are greater for renewable technologies than for CCGTs, CCGTs are preferred to renewables. The CCGTs are less needed (larger shadow price) when renewables are forced (in the "Base" scenario), and then when DSM is allowed (in the "Efficiency" scenario) because electricity demand can be reduced. In the intermediate case, there is still too much capacity (positive shadow price), but it is more useful.

Renewable technologies are preferred in the case without forced CCGTs (smaller shadow prices), because there is less installed capacity in the system and there is more coal capacity, with a high emissions factor. Among the renewable technologies, wind and biomass are the most competitive ones 
(smaller shadow price), then solid waste, and solar PV is the most expensive one.

With forced CCGTs, wind is more competitive than biomass, and the opposite is true when CCGTs are not forced. This is explained by the fact that biomass is similar to CCGTs in its operation: it is a dispatchable technology with high firmness and operating flexibility, so it is more needed in the system when there are less CCGTs.

\section{d. Electricity generation}

In Figure 2 we represent the energy production of each power generation technology in the entire year, as well as the gas outgoing from LNG regasification terminals. The total produced electricity $(0.96 \mathrm{EJ})$ is the same in all the cases where DSM is not allowed (all except the two scenarios labelled "Efficiency"), and if DSM is allowed, electricity demand reductions imply that total generation falls to 0.84 EJ (-12.6\%). Hydro and nuclear generation remain constant in all scenarios ( 0.13 and $0.24 \mathrm{EJ})$ because their very low variable costs make them very competitive. Coal generation increases, other things being equal, when CCGTs are not forced ("Iow CC" scenarios): $4.7 \%$ in the "Base" cases, $3.1 \%$ in the "No RE" cases, and $20.0 \%$ in the "Efficiency" ones. This is compensated by CCGT generation reductions: $-12.1 \%$ in the "Base" cases, $-2.2 \%$ in the "No RE" cases, and $-50.5 \%$ in the "Efficiency" ones. LNG regasification values follow those of electricity production with CCGTs, given that gas imports through gas pipelines always reach the capacity limits (shadow prices associated to those capacity constraints are always positive). Renewables production remain the same in both "Base" and "Base_low CC" cases, because resource qualities are the same and 
capacities too, which are always fully utilized (also in the case of dispatchable technologies such as biomass).



Figure 2. Electricity generation and LNG regasification in the year, measured in ExaJoules (EJ).

\section{e. Energy supply costs}

Finally, the cost components for the total energy system in each of the scenarios are analyzed, the sum of them (i.e. the total supply cost) being the objective function that is minimized. They can be seen in Table 6 . 


\begin{tabular}{|c|c|c|c|c|c|c|}
\hline Domestic primary energy production (+) & $4,129.1$ & $2,997.4$ & $4,073.3$ & $2,449.4$ & $2,189.4$ & $2,337.9$ \\
\hline Primary energy imports $(+)$ & $7,460.4$ & $9,734.5$ & $7,518.7$ & $8,370.8$ & $10,168.5$ & $8,307.9$ \\
\hline New conversion capacity investment $(+)$ & $4,934.3$ & $1,887.8$ & $1,844.2$ & $4,409.9$ & $1,497.2$ & $1,503.5$ \\
\hline Conversion capacity fixed O\&M (+) & $2,153.7$ & $1,496.2$ & $1,520.7$ & $2,229.7$ & $1,564.1$ & $1,674.4$ \\
\hline Conversion capacity variable $\mathrm{O} \& \mathrm{M}(+)$ & 778.0 & 790.1 & 730.9 & 782.6 & 792.3 & 750.4 \\
\hline Final energy exports (-) & $-1,011.0$ & $-1,011.4$ & $-1,011.0$ & $-1,010.0$ & $-1,011.7$ & $-1,012.1$ \\
\hline DSM implementation (+) & 0.0 & 0.0 & 840.0 & 0.0 & 0.0 & 840.0 \\
\hline Electricity generation reserve cost (+) & 84.2 & 64.6 & 64.6 & 103.3 & 92.7 & 64.6 \\
\hline TOTAL ENERGY SUPPLY COST & $46,092.3$ & $44,032.1$ & $41,176.9$ & $44,855.0$ & $43,348.0$ & $39,870.3$ \\
\hline Total savings (billion $€$ ) & & & & & 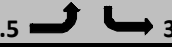 & \\
\hline
\end{tabular}

Table 6. Cost components and total energy supply cost in each scenario, Million $€$ per year.

The domestic primary energy production costs refer to coal mining and biomass production. They are smaller in the "low CC" scenarios because less domestic coal is used than in the other three ones: the model invests in imported coal capacity and thus prefers to use this fuel rather than domestic coal, which is more expensive (15.9€/MWh $\mathrm{h}_{\text {DomesticCoal }}$ vs. $\left.9.7 € / \mathrm{MWh}_{\text {ImportedCoal }}\right)$. Domestic coal in Spain is only used because of public subsidies and usage quotas, aiming mainly at maintaining jobs in the sector. In the two "Base" and the two "Efficiency" cases, more coal is used because the emissions constraint is less restrictive: there is zero-emissions renewable generation, or final energy-use emissions are smaller. The costs of primary energy imports are greater in the "low CC" scenarios due to the larger use of imported coal. Both "No RE" scenarios present bigger primary import costs because of greater gas imports, given that more electricity is produced in CCGTs, as seen above.

New conversion capacity annualized investment costs present a €3billion increment, other things being equal, when renewable technologies are forced ("Base" and "Base_low CC"), what represents their larger investment costs. These investment costs are around $€ 400$ million higher in the cases with forced 
CCGTs (the ones not marked "low CC"), other things equal. This can be seen as the cost of CCGTs excess capacity, compared to optimal investments in coal and CCGTs in each corresponding "low CC" scenario. Concerning fixed O\&M costs, what can be seen is the higher cost of renewable technologies (bigger values for this cost in both "Base" cases); and the higher cost of imported coal vs CCGTs (fixed O\&M costs around €100million larger in the "low CC" cases, under ceteris paribus comparisons). Regarding variable O\&M costs, different effects are levelled and small differences are observed in these figures.

Energy transportation costs (associated to electricity, gas, and oil products networks operation) are higher in the two "No RE" cases because of more gas being delivered to CCGTs, and lower in both "Efficiency" scenarios, where total delivered final energy is smaller due to demand reductions. Final energy imports, mainly associated with oil products imports (diesel and kerosene primarily), and which are not very much linked to the power system, are not influenced by the presence or not of CCGTs. However, they are smaller in the "Efficiency" scenarios due to demand reductions. Final energy exports, mainly electricity, are constant. Demand side management (DSM) implementation costs are the same in both cases where DSM is allowed, because the same measures are implemented. The DSM measures that are implemented by the model are the ones shown in Table 7: 


\begin{tabular}{|l|}
\hline "Eco Driving principles for car drivers" \\
"Teleconference incentives for businesses" \\
"Promote correct tyre inflation in cars" \\
"Promote fuel saving devices in cars" \\
"Promote car scrapping" \\
"Install regenerative brakes in subway" \\
"Rise fuel taxes for particular cars" \\
"Improved air traffic operations" \\
"Promote freight in ship in Athlantic coast" \\
"Rational lighting systems residential sector" \\
"Rational heating systems residential sector" \\
"Efficient electronics residential sector" \\
\hline
\end{tabular}

Table 7. Demand side management policies chosen by the model.

Finally, electricity reserves costs (calculated as the variable O\&M cost of idle capacity that is providing reserves and thus not producing electricity), are higher in the case with renewables, because more reserves are needed in the system due mainly to wind intermittency. As said above, the reserves needed in the system are the addition of the capacity of the largest power plant that could fail and the uncertainties associated to the predictions of demand and intermittent generation. Of these, the two first parameters (related to plant failure and demand uncertainty) are constant in all scenarios whereas the one associated to intermittent generation only exists in the "Base" scenarios, making the need for reserves to grow. The large presence of CCGTs in the system in the scenarios not marked as "low CC" is useful to provide inexpensive reserves to the system, given this technology's flexibility and small variable O\&M costs. In the cases without mandated CCGTs, reserves are provided by fuel-gas generators, hydro power plants and by the lower CCGT capacity. Unsupplied energy (used as the model's slack variable as seen above) is null in all cases, so its penalization is zero. 
Combining all the effects above, and focusing on the cases with the actual CCGT investment (the ones not marked as "low CC"), it can be seen that yearly costs in the "Base" case (the one representing the actual situation) are $€ 2.1$ billion higher than without mandated REs, everything else being equal. This result approximates well the actual 2008 REs support cost (associated to feed in tariffs and premiums), which according to the Spanish Energy Regulatory Commission was €2.3 billion (Comisión Nacional de Energía, 2009). Implementation of DSM policies instead of RE support results in net savings of $€ 5$ billion: $€ 2.1$ billion of RE promotion and $€ 2$.9billion of lower costs of meeting the reduced demand (net of DSM implementation cost).

In the scenarios without mandated CCGTs ("low CC" cases), similar conclusions can be drawn. Implementation of DSM instead of RE support would also imply net savings of $€ 5$ billion: $€ 1.5$ billion of savings in RE support and $€ 3.5$ of lower costs of meeting demand.

In the scenarios with actual CCGT capacity, the extra costs of RE support are greater than in the case without mandated combined cycles (€2.1 billion vs. $€ 1.5$ billion). This is because in the second case there is less capacity in the system, and the electricity mix is more carbon-intensive (more presence of coal). Thus, if CCGTs investment had not been as important, renewables would be less expensive for the system.

In both cases it can be seen that total costs are bigger with forced REs, and that when DSM measures are applied, the savings (mainly in energy imports) are 
larger than the promotion costs, causing the total system's costs to fall, as expected from the literature (Enkvist et al., 2007), (Gillingham et al., 2006).

Total systems costs are larger in the cases with mandated combined cycles than in the equivalent ones without forced CCGTs. This fact, along with other results seen above, points at the large amount of these power plants being suboptimal.

The savings of DSM implementation are smaller in the scenarios with actual CCGT capacity: $€ 2.9$ billion vs. $€ 3.5$ billion in the "low CC" cases. This is mainly because, when DSM is used, final energy use emissions fall due to demand reduction, and the model then generates more electricity with expensive domestic coal, incrementing domestic primary energy production costs. This effect is much larger in the cases with 21 GW of CCGTs: the excess capacity in the system prevents the model from investing in imported coal generation and therefore fosters national coal usage. Hence, the greater flexibility of the model in deciding the power generation portfolio in the "low CC" cases increases the benefits of DSM. In other words, an optimal electricity generation mix allows for full exploitation of DSM benefits.

\section{Conclusions}

The aim of this study was to analyze whether renewable electricity promotion in Spain has been or not the most cost-efficient means of reducing carbon emissions, when compared to the promotion of energy efficiency in sectors such as transport or buildings. For this purpose, an ex-post study of the 
evolution of the Spanish energy system over the years 1996 to 2008 has been carried out.

Our study has revealed that the implementation of DSM instead of renewables for the reduction of $\mathrm{CO}_{2}$ emissions results in net savings of $€ 5$ billion a year, both with the actual level of investment in CCGTs and with an optimal (lower) CCGT capacity. Hence, if minimizing the cost of reducing emissions is the major concern, DSM measures clearly dominate renewables promotion. Of course, RE present other important advantages for society that are not considered here, such as industrial activity or technological development, which will potentially bring large benefits in the longer term (in scenarios where energy efficiency potential is almost fully utilised and where renewables are therefore needed, e.g. to largely decarbonise energy sectors).

One element that muddles a bit the analysis of the optimal policy is that the existing investment in new CCGT capacity $(21 \mathrm{GW})$ is too large, according to the results. The shadow price of the constraint that forces the model to invest at least $21 \mathrm{GW}$ is always positive. Indeed, without mandated CCGTs, the model installs between 3 and $10 \mathrm{GW}$ (less than the actual 21GW), depending on the case, and total costs are lower. Combined cycles are being helpful in providing operating reserves to the system, but this does not justify the large existing volume of CCGT investment.

In fact, and interestingly, this paper's main result is also contingent on the evolution of CCGT capacity. Although the main conclusion remains the same (DSM dominates RE for emissions reduction in both groups of scenarios), the 
extra cost of renewables for the system would be less, and the benefits of DSM would be greater, if the large investment in CCGTs had not occurred.

To sum up, and answering this paper's research question, demand side management clearly dominates renewable support instruments if our goal is to reduce carbon emissions to some extent at the lowest cost. Therefore, a natural policy conclusion is that, in this case, energy efficiency policies should be prioritised well above renewable energy promotion ones. This conclusion may still hold under other circumstances, since energy efficiency can also contribute to economic development or technological advances. However, it is also clear that energy efficiency cannot completely eliminate energy consumption. Therefore, if the goal is to have an almost fully decarbonised energy sector, renewables are also required in this second, more aggressive stage, which in turn may ask for support policies that promote their technological development. The question then that can be asked is what should be the share of energy efficiency and renewables in this scenario, and how to coordinate their support policies to achieve the desired result at the lowest cost. More research is clearly needed to address this question.

\section{References}

Batlle, C., Vázquez, C., Rivier, M., \& Pérez-Arriaga, I. (2007). Enhancing Power Supply Adequacy in Spain: Migrating from Capacity Payments to Reliability Options. Energy Policy, 35(9), 4545-4554. doi:10.1016/j.enpol.2007.04.002

Comisión Nacional de Energía. (2009). Boletín Mensual de Indicadores Eléctricos y Económicos. Febrero 2009. 
de la Villa, A. (2010). Propuestas sectoriales de políticas de eficiencia energética en el sector del transporte (Proyecto Fin de Carrera). Universidad Pontificia Comillas, Madrid.

Ecofys, E3Mlab of ICCS/NTUA, Institute for Prospective Technological Studies JRC European Commission, AEA Energy and Environment, \& CE Delft. (2009). SERPEC-CC Project. Summary: Ambitious Emission Reductions Will Be Cost-Neutral for the EU. SERPEC-CC Project Reports. Retrieved from http://www.ecofys.com/en/publications/133/

Enkvist, P.-A., Nauclér, T., \& Rosander, J. (2007). A Cost Curve for Greenhouse Gas Reduction. McKinsey Quarterly, 1, 34.

Fishbone, L. G., \& Abilock, H. (1981). MARKAL, A Linear-Programming Model for Energy Systems Analysis: Technical Description of the BNL Version. International Journal of Energy Research, 5(4), 353-375.

Fraunhofer ISI, ENERDATA, Institute of Studies for the Integration of Systems ISIS, Vienna Technical University, \& Wuppertal Institute for Climate, Environment and Energy WI. (2009). Study on the Energy Savings Potentials in EU Member States, Candidate Countries and EEA Countries. Final Report.

Gillingham, K., Newell, R., \& Palmer, K. (2006). Energy Efficiency Policies: A Retrospective Examination. Annual Review of Environment and Resources, 31, 161-192.

Greening, L. A., Greene, D. L., \& Difiglio, C. (2000). Energy Efficiency and Consumption the Rebound Effect - a Survey. Energy Policy, 28(6-7), 389-401. doi:10.1016/S03014215(00)00021-5

Instituto para la Diversificación y Ahorro de la Energía. (2009). Informe Anual de Consumos Energéticos Año 2008.

Labriet, M., Cabal, H., Lechón, Y., Giannakidis, G., \& Kanudia, A. (2010). The Implementation of the EU Renewable Directive in Spain. Strategies and Challenges. Energy Policy, $38(5), 2272-2281$. 
Linares, P., Santos, F. J., \& Pérez-Arriaga, I. (2008). Scenarios for the Evolution of the Spanish Electricity Sector: Is It on the Right Path Towards Sustainability? Energy Policy, 36(11), 4057-4068.

Linares, P., Santos, F. J., Ventosa, M., \& Lapiedra, L. (2006). Impacts of the European Emissions Trading Scheme Directive and Permit Assignment Methods on the Spanish Electricity Sector. The Energy Journal, 27(1), 79-98.

López-Peña, Á., Linares, P., \& Pérez-Arriaga, I. (2011a). Renewables in the Spanish Energy Sector: a Cost-Efficiency Evaluation for CO2 Emissions Reduction. Presented at the Workshop "The Cost of Renewable Energy in the EU," European University Institute, Florence, Italy.

López-Peña, Á., Linares, P., \& Pérez-Arriaga, I. (2011b). POEMS: a Policy-Oriented Energy optimization Model with Sustainability considerations. Working Paper IIT-11-157A.

Lorenzo, J. (2010). Propuestas sectoriales de políticas de eficiencia energética en el sector residencial (Proyecto Fin de Carrera). Universidad Pontificia Comillas, Madrid.

Loulou, R., Remne, U., Kanudia, A., Lehtila, A., \& Goldstein, G. (2005). Documentation for the TIMES Model, Part I: General Description of the TIMES Paradigm.

Mendiluce, M., \& Schipper, L. (2011). Trends in Passenger Transport and Freight Energy Use in Spain. Energy Policy, 39(10), 6466-6475. doi:10.1016/j.enpol.2011.07.048

Mendiluce, M., Pérez-Arriaga, I., \& Ocaña, C. (2010). Comparison of the Evolution of Energy Intensity in Spain and in the EU15. Why Is Spain Different? Energy Policy, 38(1), 639-645. doi:10.1016/j.enpol.2009.07.069

Ministerio de Fomento. (2011). Plan de Ahorro, Eficiencia Energética y Reducción de Emisiones en el Transporte y la Vivienda. Gobierno de España.

Ministerio de Industria, Turismo y Comercio. (2011). Plan de Acción de Ahorro y Eficiencia Energética 2011-2020. 
Ministerio de Medio Ambiente y Medio Rural y Marino. (2011). Inventario de Emisiones de Gases de Efecto Invernadero de España. Años 1990-2009. Madrid.

Red Eléctrica de España. (2009). El Sistema Eléctrico Español 2008.

Sorrell, S., Dimitropoulos, J., \& Sommerville, M. (2009). Empirical Estimates of the Direct Rebound Effect: A Review. Energy Policy, 37(4), 1356-1371. doi:10.1016/j.enpol.2008.11.026

WWF Spain. (2010). Potencial de ahorro energético y de reducción de emisiones de CO2 del parque residencial existente en España en 2020.

\section{Footnotes:}

${ }^{1}$ In a linear programming problem, the shadow price associated to a constraint expresses the marginal worsening/improvement of the problem associated to the constraint. By definition, shadow prices take a zero value when the constraint is not active.

${ }^{2}$ Each of these constraints has been modeled, in the GAMS code, using two constraints simultaneously: a greater than and a less than constraint, that applied simultaneously is mathematically equivalent to an equals constraint. 